\title{
A religião como comunicação na era digital*
}

\author{
Religion as communication in the digital age
}

\author{
Enzo Pace** \\ Giuseppe Giordan***
}

\begin{abstract}
Resumo: Na era digital, as ciências sociais da religião começaram a enfrentar o problema de estudar um fenômeno novo e complexo: a comunicação religiosa mediada pelo computador. A Sociologia precisa encontrar instrumentos, categorias e metodologias para analisá-lo. Neste ensaio, nos concentramos no estado da arte do fenômeno e, também, em discutir a terminologia e sugerir uma metodologia de classificação e algumas orientações de leitura. Na verdade, o ciberespaço não é uma questão de trazer ordem para o "infinito sem sentido do real", mas de ter em conta que as realidades são, no mínimo, duas e que, a partir de muitos pontos de vista, elas não pertencem sempre ao mesmo "mundo". A noção de religião oferece rígidas evidências sociolinguísticas para o pesquisador, talvez mal-apropriado para estudar as comunidades virtuais de crença, com limites efêmeros e mutáveis, grupos de pessoas reunidos apenas na rede, sem qualquer conexão real com o outro.
\end{abstract}

Palavras-chave: religião; comunicação; internet

\begin{abstract}
In the digital age, the social sciences of religion have begun to face the problem of studying a new complex phenomenon: religious communication mediated by the computer. Sociology needs to find instruments, categories and methodologies to analyze it. In this essay we focus on the state of the art of the phenomenon, discussing the terminology, and suggesting a classification methodology and a few reading guidelines. Indeed the cyberspace it is not a matter of bringing order into the "meaningless infinity of the real", but of bearing in mind that the realities are at least two and that, from many points of view, they not always belong to the same "world". The notion of religion offers rigid socio-linguistic evidences to the researcher, perhaps ill-suited to study virtual communities of belief, with ephemeral and changing boundaries, groups of people meeting only in the Net, without any real connection with each other.
\end{abstract}

Keywords: religion; communication; internet

\footnotetext{
*Enzo Pace redigiu a Introdução e os itens 1, 2 e 3; Giuseppe Giordan redigiu o item 4.

** Doutor em Filosofia pela Universidade de Padova e professor de Sociologia da Religião da Universidade de Pádua. <vincenzo.pace@unipd.it>.

*** Ph.D. pela Pontifícia Universidade de São Tomás de Aquino (Roma) e professor de Sociologia na Faculdade de Ciências Políticas da Universidade de Pádua. <giuseppe.giordan@unipd.it>.
}

\begin{tabular}{|l|l|l|l|l|l|}
\hline Civitas & Porto Alegre & v. 12 & n. 3 & p. 418-438 & set.-dez. 2012 \\
\hline
\end{tabular}




\section{Introdução}

O presente ensaio tem como finalidade a análise de um novo fenômeno no campo das ciências sociais da religião: a comunicação religiosa mediada pelo computador. A pesquisa até agora colocou em evidência a extensão e a complexidade do próprio fenômeno; em outras palavras, nos interrogamos tanto sobre como estudá-lo quanto com que modelos teóricos analisá-lo. De fato, nos encontramos diante de um objeto que tem, pelo menos, três dimensões que se sobrepõem e que nem sempre é fácil distinguir: a comunicação (via computador), a religião e a observação. O que estamos observando é um específico processo comunicativo que tem por objeto conteúdos relacionados com aquilo que chamamos convencionalmente religião ou é uma forma moderna de expressividade religiosa, que encontra exatamente em um sítio web seu estado nascente? Além disso, desde que a observação seja feita sobre novas formas de comunicar a religião via computador, com qual metodologia pode ser enfrentada sua análise, já que uma coisa é examinar com uma pluralidade de métodos (análise semiótica, icônica, do conteúdo, dos estilos retóricos, do eixo semântico opositivo e assim por diante) como um sítio foi construído e, também, quem o construiu e com quais finalidades (manifestas e/ou implícitas), outra coisa é entender quem tem acesso ao sítio, com quais expectativas, por quanto tempo, por quais finalidades (por pura informação ou por uma efetiva necessidade de "religião"); neste caso, é realmente árduo sondar em termos quantitativos o perfil sociocultural e socioeconômico dos usuários (mas esta palavra, como bem se compreende, torna-se genérica demais para classificar uma plateia vasta e anônima de consumidores de um bem religioso via computador), tanto que até agora nos limitamos a nos concentrar nos sítios que oferecem um espaço interativo (chat, fórum, facebook etc.) e a estudar que tipo de comunicação e de relações por via eletrônica se estabelece com indivíduos dos quais, na verdade, conhecemos somente o que dizem digitando em seu teclado pessoal. Quanto mais se expandem e se diferenciam as formas de comunicação mediada pelo computador - como, por exemplo, com a difusão do youtube -, tanto mais torna-se complexo preparar instrumentos de levantamento eficazes, capazes de atuar nas duas pontas do fenômeno: a sua qualidade provisória e variável no tempo (um sítio pode existir hoje e não mais amanhã), por um lado, e sua estrutural precariedade e vulnerabilidade no que diz respeito ao princípio de autoridade. Quem decide que um sítio deva se apresentar de uma determinada maneira não sabe, de fato, se ele será efetivamente utilizado de acordo com sua vontade inicial e o risco da dupla contingência é muito mais elevado em relação a religiões institucionais que 
estão presentes visivelmente na realidade social: ego não sabe se alter aceitará comunicar conforme o código que ego pensou no início e, vice-versa, alter não sabe se a forma com que interpreta o sentido veiculado via computador pode ser re-con-duzido ao esquema comunicativo de ego.

A nossa proposta, portanto, é mostrar as problemáticas encontradas pelo pesquisador quando, ligando um computador e navegando em um oceano de sítios dedicados à religião/espiritualidade, logo percebe a necessidade de se dotar de teorias e métodos adequados para um objeto tão complexo como aquele das religiões em rede.

Especificamente, tentaremos avaliar se, e até que ponto, a teoria dos sistemas pode constituir um bom viático heurístico na compreensão - no significado próprio que Max Weber dava a este termo, como arte de cumprendere, de reconduzir dentro de ideal-tipos de comunicação assistida pelo computador os esparsos e fragmentados elementos que a realidade (no nosso caso o virtual) apresenta em matéria de religião. E, além disso, fornecer indicações de método para futuras pesquisas no campo do virtual.

Mencionaremos, por fim, como o recente debate que se desenvolveu na sociologia da religião sobre a relação entre religião e espiritualidade ajuda a compreender, exatamente a partir da webreligion, algumas dinâmicas atuantes na relação entre o indivíduo e o sagrado.

\section{$O$ estado da arte}

A religião como comunicação mediada pelo computador (RCMC) tornou-se um objeto de estudo sobre o qual convergem especialistas de diferentes disciplinas: desde os especialistas em comunicação e em novas tecnologias até os sociólogos, dos semiólogos aos psicólogos e, por fim, dos informáticos aos linguistas. A atenção foi crescendo nos últimos quinze anos, principalmente desde quando houve uma maciça entrada na internet de uma pluralidade de atuantes religiosos que entenderam as potencialidades do instrumento para ampliar o raio de sua ação comunicativa (comunica-ação). Nisso tudo, em uma primeira aproximação, não houve nada de novo em relação a um recente passado, quando grandes igrejas ou pregadores independentes utilizaram amplamente os meios de comunicação de massa, como o rádio, antes, e a televisão, mais tarde. Lembramos, por dever de memória, a sorte dos telepregadores nos Estados Unidos, entre 1970 e 1990: eles inventaram o que na literatura foi chamado de igreja eletrônica, um modelo que logo foi imitado sucessivamente na América Latina com o nascimento de novas igrejas de inspiração pentecostal (as quais confiaram e confiam uma parte de seu sucesso à implantação de eficientes instalações televisivas de onde 
irradiam sua mensagem), assim como em alguns países africanos onde o pentecostalismo de terceira geração difundiu-se amplamente - por exemplo, em Ghana (Asamoah-Gyadu, 2005) ou na Nigéria. Ao mesmo tempo, se multiplicaram locais ou espaços eletrônicos na Internet que acolheram desde 1980 boletins, revistas e jornais eletrônicos produzidos por igrejas ou grupos religiosos com amplo reconhecimento no ambiente social de referência ou para fazer circular ideias, mensagens éticas e teológicas, como aconteceu com os sítios Usenet de conteúdo religioso. Em todos estes casos, ainda que com diferenças às vezes não irrelevantes de um sítio para outro, o fluxo da comunicação seguia o esquema clássico emissor $\leftrightarrow$ receptor: quem produzia a comunicação se preocupava de alcançar mais facilmente um potencial amplo grupo de usuários de internet. Quando um "telepregador" interage com os fiéis-seguidores de seus programas, convidando-os a subscrever e doar fundos para a igreja eletrônica que ele criou, estamos diante do poder da palavra que um líder carismático consegue incrementar (e consegue mensurar com base não somente na audiência, mas no fluxo de dinheiro que entra no seu caixa), graças à eficácia do meio televisivo; meio que, entrando em todas as casas, pode estabelecer um contato com o fiel em poltrona e conquistar sua confiança, talvez antes até de confiar sua fé. A confiança é medida pelo fato que ele não muda de canal e permanece fielmente grudado à tela durante todo o desempenho do próprio pregador. Esta fé visionária evidentemente pressupunha e pressupõe uma postura de preliminar, vaga aceitação da mensagem, conforme uma das premissas teóricas da própria comunicação: não é o meio em si que cria uma opinião; ele reforça e torna plausível esta opinião em uma pessoa que decide livremente ligar o televisor e escolher um canal no lugar de outro (aquele canal específico que ele considera ideologicamente e emotivamente mais próximo ao seu modo de sentir e de pré-compreender a realidade).

O fiel em poltrona pode até não frequentar a igreja; a palavra (sagrada) entra, todavia, na sala em que está comodamente sentado e o convence, ou porque, no fundo, já estava convencido ou porque estava predisposto a se deixar convencer. A palavra dada através do meio televisivo é uma palavra acolhida, porque ela parece fun-dada aos olhos (e aos olhos da mente) de quem é só (aparentemente) espectador. Ele não é um ingênuo. O fato de acreditar é seletivo. Nos mapas cognitivos de cada um de nós ele pode ocupar um lugar central ou marginal e variar conforme as situações, o ciclo de vida, as condições sociais, os eventos coletivos ou as experiências individuais, intimamente impossíveis de repetir.

O fiel em poltrona é parecido com a figura que Elihu Katz e Daniel Dayan (1984) estudaram: a peregrinação na poltrona. Ele se coloca no âmbito de uma 
mais ampla teoria dos media event (1992), que na Itália foi retomada e aplicada na ocasião das viagens de João Paulo II por Guizzardi (1986). Neste caso um fato interno da igreja católica, a viagem de um Papa pelo mundo, tornava-se um evento midiático, uma narração televisiva que reforçava o carisma de uma figura como foi aquela do Papa Wojtyla. A estrutura narrativa alcançou seu apogeu próximo à morte, quando as televisões do mundo inteiro seguiram com um crescendo de emoção e paixão o fim do Papa polonês (Guizzardi, 2005). Nos eventos midiáticos, todavia, havia um elemento que antecipava a evolução atual da religião como comunicação mediada pelo computador. Eles eram ampliados pelo próprio meio televisivo, que a partir do conto pontual de um fato passava à construção de um plexo de contos ligados (entrevistas com as pessoas que assistiam, comentários de importantes personagens públicos, debates, repetições de sequências nos telejornais, transmissões especiais sobre o evento e assim por diante). Uma vez estabelecida a trama do conto, ele podia durar muito tempo, ou melhor, na linguagem da comunicação de massa, estava em condições de se reproduzir no tempo explorando a onda emotiva que ele havia despertado no início e que havia criado em torno do mesmo uma mobilização emotiva. Deste modo se criava uma constante participação em poltrona.

\section{Além da distinção entre religion on line e online religion}

Os anos oitenta do século recém transcorrido, deste ponto de vista, foram interessantes para compreender a retomada não tanto da religião, quanto do interesse por parte das grandes mídias quanto ao fenômeno religioso. Algo de parecido aconteceu com outro evento, que para Heidi Campbell (2005), uma estudiosa do Departamento de Comunicação da Universidade do Texas, assinala o ponto de mudança nos processos de comunicação da religião via internet. Trata-se do dramático final da expedição aeroespacial do Challenger em janeiro de 1986. Além das manifestações públicas e das numerosas transmissões televisivas apresentadas nos principais canais, foi lançado com grande sucesso um network de comemoração na internet - chamado Unison -, no qual os organizadores ofereciam aos usuários, que podiam acessar livremente, um conjunto de serviços litúrgicos cuidados por diversos líderes religiosos, com meditações, preces, sermões e apelos à solidariedade cristã, também um coffee hour, um espaço livre, em que as pessoas que tinham acompanhado a programação via internet podiam enviar seus comentários ou expressar seus sentimentos, comparando e comunicando entre si. De acordo com Lochhead (1997) tudo isso demonstrou quão eficaz fosse o poder da comunicação mediada pelo computador ao criar um sentimento de 
pertencimento coletivo e um espírito de coesão social, além das diversidades de cor e religião.

Entre 1995 e os nossos dias, a atenção dos estudiosos se deslocou cada vez mais da TV para a internet. O primeiro estudo com alguma relevância, de fato, tem a data de 1996, com o trabalho de O'Leary e Brasher (1996). Hadden e Cowan (2000) meritoriamente definiram a situação das principais abordagens e das problemáticas metodológicas que emergiram até agora e que foram testadas pela pesquisa, enquanto devemos a Helland (2000) a primeira tentativa de começar a colocar ordem no fenômeno, introduzindo a distinção entre religion online (instituições religiosas que se adaptam a comunicar via internet) e online religion (criação de novas networks capazes de promover a formação de comunidades virtuais nas quais a definição dos conteúdos e dos significados religiosos ou espirituais é confiada à interação via computador entre os indivíduos). Esta distinção, que nos escritos mais recentes o próprio autor atenuou (Helland, 2005, 2007), no fundo, olhando bem, resume as novas perspectivas que a internet parece abrir às religiões: se com o primeiro modelo (religion online) ainda estamos diante da sequência emissor-receptor, no segundo (online religion) estamos diante de uma relevante mudança sociocultural, já que um sítio deste tipo oferece um espaço criativo e interativo para uma vasta (mais ou menos anônima) plateia de usuários, os quais, deste modo, dão a ideia de fazer para si uma religião sob medida. Tudo isto é diferente da noção de bricolage que alguns usaram muitas vezes para classificar as novas modernas formas de crer. Tal noção remete à ideia de que a religião, tornando-se objeto de escolha individual (pela qual o estatuto de verdade de um credo não tem mais um fundamento objetivo em uma tradição, ou em uma revelação, ou em uma autoridade magistral, em um guru espiritual e assim por diante), é submetida a um processo de redefinição contínua de seus conteúdos e de suas aplicações à vida ou aos estilos de vida dos indivíduos (Berzano, Genova, 2008). Poderíamos cunhar uma nova sigla para marcar a diferença entre a noção clássica, tal como chega a nós pelos estudos de Levy-Strauss e pelos primeiros estudos sobre a secularização de Berger e Luckmann, e o novo cenário que se abre com a era digital; essa sigla poderia ser bricorelnet, em que o bricolage religioso via internet parece caracterizado por uma mais elevada possibilidade oferecida aos indivíduos que têm acesso à internet de interagir livremente, de produzir com as próprias mãos (ou melhor, com os próprios dedos...) uma pluralidade de significados a serem atribuídos a um conjunto de símbolos, rituais e crenças de conteúdo religioso. Estamos diante de um agir comunicativo (uma comunica-ação) que torna visível representando-o dramaturgicamente no palco mediático da internet - o desvio 
do sentido que existe entre um sistema de crença reconhecido histórica e socialmente, se não por outros motivos pelas estáveis instituições que ele conseguiu criar e reproduzir no longo espaço da história, e a pluralidade dos ambientes em relação aos quais um sistema se esforça para se constituir como fonte única do próprio sentido.

A teoria dos sistemas, a tal propósito, nos fornece alguns instrumentos úteis de análise, que pela ordem são:

a) se assumimos a ideia que uma religião é um sistema de crença simbólico, ele deve interagir continuamente com um ambiente (social e simbólico) mais amplo, diferenciado e variável em relação ao próprio sistema;

b) o desvio na relação entre sistema e ambiente - relação que constitui o objeto da observação sociológica - diz respeito precisamente à questão do sentido: um sistema de crença tende a selecionar os significados a serem atribuídos àquilo que a verdade do crer define ou gostaria de definir de uma vez e para sempre (conforme o ponto de vista do próprio sistema, obviamente), mas o ambiente é um campo aberto onde são dados múltiplos, variáveis e contrastantes outros significados que podem ser atribuídos a um mesmo objeto ou conteúdo do crer;

c) no caso das religiões em rede tal desvio é ampliado, pois um sítio religiosamente sinalizado (por seus conteúdos explícitos, pela iconografia que utiliza, pelo design geral com que se apresenta com o objetivo de tornar a própria oferta visível e diferente ao mesmo tempo em um mercado virtual de bens simbólicos de salvação) (Stolz, 2008) é de qualquer forma um ambiente virtualmente colocado à disposição por quem, em nome e por conta de um determinado sistema de crença, decide abrir-se ao risco do sentido, à produção não controlada do sentido por parte de quem não crê ou crê pouco ou crê de modo próprio (em relação à autorrepresentação do próprio sistema). Se para um sistema em rede a verdade é uma dúvida resolvida, para o ambiente virtual que de fato ele cria a verdade é um livro eletronicamente aberto no qual, quem quer que seja, pode reabrir a porta da dúvida. A pluralidade dos significados pode formalmente ser aceita ou excluída. Todavia, mesmo quando não há espaço para expressar dúvidas e polissemias no ambiente virtual criado por um sistema (pequeno ou grande pouco importa, neste momento), o risco do sentido não pode ser reduzido. No esquema da comunicação, tal como é definida pela teoria dos sistemas, entre ego e alter, de fato, o 
primeiro oferecendo-se como ambiente virtual expõe-se ao risco que o segundo navegue em seu interior sem se deixar reduzir ao código de significados que o sistema possui para poder funcionar como tal; se os sistemas de crença religiosos na relação com o ambiente podiam, antes da era digital, manter a diferença com o ambiente (externo), agora, ficando na rede, correm o risco de perder esta possibilidade, porque se abrem - até demais, talvez - à multiplicidade e variabilidade do entendimento subjetivo de tantos anônimos e potenciais visitantes. O poder da palavra, que de muitas maneiras constitui a quintaessência da religião como comunicação, pode perder a potência em favor da visão assistida pelo computador. Ver para crer coloca em crise a palavra dada - como depósito de símbolos e gestos rituais transmitidos ao longo da corrente da memória religiosa (HervieuLèger, 1993), no sentido que entrando em qualquer sítio posso livremente interpretar os símbolos, os desempenhos litúrgicos que me são oferecidos, as mensagens ideológicas que são por ele veiculadas, atribuindo-lhes uma pluralidade de significados que, em princípio, não coincidem necessariamente com aqueles definidos por quem teve interesse em abrir um ambiente virtual no qual mostrar que existe.

\section{Por uma tipologia dos sítios em base religiosa}

Em todo caso as net-religiões, sejam no primeiro (relonline) ou no segundo modelo (onlinerel), por meio da nova linguagem oferecida pela informática e pela digitalização, se expandem, no sentido que, para usar um paradoxo, enquanto as igrejas se esvaziam, os locais virtuais - os sítios religiosos - parecem encher-se (Mit Communications Forum, 2002; Young, 2004; Højsgaard, Warburg, 2005). Se, por exemplo, em 1988 entre cem igrejas mainstream nos EUA somente 11 estavam presentes na web, em 2002 passaram a 45\% (Thumma, 2002). Sempre como exemplo, só para ter uma pálida ideia de quantos sítios de tipo religioso estejam presentes na web, basta consultar o Open Directory Project, acessando por meio do Google a página DMOZ (o acrônimo significa Directory Mozilla), que é administrada por Net_Scape Communication Corporation: aqui se encontra a informação relativa a uma classificação especial dos temas numericamente mais representados na rede web. Pode-se ver que o tema Religion and Spirituality [Religião e Espiritualidade] satura, na data da consulta (agosto 2009), 102.968 diferentes sítios; ele resulta no segundo lugar na rubrica Society [Sociedade] (que está no primeiro com 239.920 sítios), rubrica que inclui mais 37 itens. Só para ter um termo de comparação, no terceiro lugar encontramos Education [Educação] 
(43.717) e no quarto Organizations [Organizações] (15.513). Entrando no verbete Religion and Spirituality encontramos 36 itens, que vão das principais religiões àquelas menos conhecidas (ex.: Cao Dai, Falun Dafa, Fourth Way, Noahdism). Na classificação dos sítios ligados às diferentes religiões recenseadas, o item Christianity [Cristandade] ocupa o primeiro lugar (77.933) com grande vantagem sobre os outros itens. No segundo e terceiro lugar, nesta classificação ideal, encontramos respectivamente Esoteric and Occultism [Esoterismo e Ocultismo] (2.322) e Judaism [Judaísmo] (2.271). Pode ser interessante assinalar que antes do Islamismo e do Hinduísmo, o item que sobressai depois da terceira posição é Paganism [Paganismo]. Cada um destes verbetes remete, com links sucessivos, a outros sítios, incluindo os fóruns ou os sítios usenet (ágoras informáticas onde se confrontam e se chocam pontos de vista diferentes sobre esta ou aquela religião ou sobre um aspecto específico da mesma). Além disso, para lá dos itens claramente referidos a religiões ou crenças religiosas e não, o verbete Religion and Spirituality inclui uma segunda parte, composta por outros 36 itens de tipo temático, como, por exemplo, Mysticism, Interfaith, Prophecies, Philosphy of Religion, Reincarnation, Workplace Spirituality etc. Por fim, há um último link aos sítios catalogados por áreas linguísticas (do africânder ao farsi, do galiciano a taiwanês, do malaio ao tâmil...), 69 para ser exato, com uma classificação também curiosa que vê em primeiro lugar o japonês, no segundo o alemão, no terceiro o espanhol, no quarto quase empatados o holandês e o russo e no quinto o italiano. Aquilo que, todavia, constitui um campo de pesquisa empírica de grande interesse é usenet, redes de discussão livres (de acesso e recesso voluntário) sobre assuntos religiosos. Os principais são, pela ordem: soc.religion, talk-religion.misc, alt-religion. Também neste caso, só para dar uma ideia da relevância destas redes para a pesquisa sobre a religião como comunicação, no sítio talk.religion entre 31 de julho e 12 de agosto de 2009, o grupo de discussão sobre assuntos vários de tipo religioso tinha recebido 61.916 intervenções e em alt.religion, no item Scientology, havia 309.652 mensagens.

O Pew Forum (2002), um instituto de pesquisa norte-americano que há anos segue com investimentos conspícuos a pesquisa sobre novos fenômenos socioreligiosos no mundo, realizou em 2002 uma enquete com uma amostra representativa da população americana para sondar se e até que ponto os americanos recorrem à internet, seja para adquirir informações sobre religião e espiritualidade, seja para conectar-se com networks independentes de tipo interativo. Os resultados são eloquentes: havia mais de 28 milhões de americanos ( $25 \%$ da população) que os pesquisadores chamaram de Religion 
Surfers (religio-nautas, poderíamos traduzir) na data da enquete. Houve um incremento de quatro pontos percentuais em relação a dois anos anteriores, quando foi feito o primeiro levantamento. Quatro sobre dez, embora tendo declarado que no passado não haviam usado internet em relação com sítios religiosos, afirmam que enviam pedidos de orações a vários endereços online. A maioria, de acordo com os pesquisadores do Pew Forum, é de navegadores solitários: eles usam a rede como uma espécie de grande biblioteca para obter informações, em parte relativamente à própria fé de nascimento, em parte para conhecer outras. Uma minoria não tão pequena - 15\% - declara ter melhorado a própria atitude e as próprias convicções em relação à religião graças à internet e quase a metade afirma que internet facilita o acesso a sítios onde é possível rezar ou realizar uma performance litúrgica. A sociedade americana que foi a pioneira tanto com o tele-evangelismo quanto com a construção das megaigrejas (uma espécie de grandes shoppings do espírito e não só do espírito, que hoje alcançaram o número de 1328 lugares espalhados principalmente na Bible Belt [Cinturão da Bíblia]) (Fath, 2008), é um laboratório onde estudar as transformações que a internet ou a CMC (Comunicação mediada pelo computador) estão produzindo no variegado mundo das religiões. Para ter uma ideia do que está acontecendo bastará lembrar a formação em 2004 (na realidade o centro nasceu em 1984 com propósitos menos ambiciosos) de um centro de pesquisa, o Barna Research Group (do nome do fundador George e sua esposa Nancy), com sede em Ventura na Califórnia, que se especializou na assim chamada Visionary Research [Pesquisa Visionária]. Ele oferece pesquisas de mercado para igrejas e ministros de culto que têm intenção de transformar sua ação pastoral utilizando internet e os novos meios da CMC: em resumo, fornecendo consultoria para revitalizar empresas religiosas desgastadas em novas empresas espirituais capazes de competir no mercado da comunicação com outras agências espirituais e religiosas (2001).

O exemplo da First Church of Cyberspace (http://www.godweb.org/sact. html) oferece uma ideia de como um sistema de crença, expondo-se até o fim à lógica da $\mathrm{CMC}$, possa mudar a própria estrutura e o próprio princípio de funcionamento. Este caso é indicativo de uma tendência: a ideia que está crescendo, de fato, entre muitos ministros de culto nos EUA e, por efeito mimético, também em outros lugares e não somente em âmbito cristão, é precisamente a convicção que a rede possa constituir um método para expandir as possibilidades oferecidas às pessoas de praticar uma fé permanecendo $\mathrm{em}$ sua própria casa. Uma privatização da religião sem o eclipse do sagrado. Trata-se somente de um exemplo entre os milhares e milhares de sítios que 
poderiam ser analisados de maneira comparada, para chegar a um primeiro tipo, ou melhor, a delinear alguns dos ideal-tipos de comunica-ação.

A partir da primeira sumária distinção proposta por Helland acima, podemos então, para começar a nos orientar no oceano da web religiosa, distinguir pelo menos quatro modelos comunicativos que, por comodidade expositiva, sintetizamos no quadro seguinte (n.1). Os critérios que usamos para chegar a uma classificação abstrata são:

1) distinguir sistemas de crença religiosa com base no fato de serem institucionais (as religiões online, no nosso caso) ou não institucionais (as online religiões), entendendo, para os primeiros, universos simbólico-religiosos organizados, com uma relativa longa história transcorrida, socialmente visíveis e reconhecíveis em diversos ambientes (incluindo tanto as assim chamadas grandes religiões mundiais, de que falava Max Weber, quanto as pequenas e médias organizações religiosas radicadas em um território ou representativas de histórias de minorias ou expressões de tendências sectárias ou, por fim, pertencentes àquela galáxia das novas formações socioreligiosas que se afirmaram no mercado dos bens religiosos nos últimos cem anos) e, para os segundos, produtos simbólicos criados especificamente para o mercado da web, adaptados ao ambiente eletrônico e funcionando como meios da comunicação assistida por computador, tal como outros produtos que circulam livremente na web;

2) distinguir entre sistemas de crença institucionais e não, de acordo com sua diferenciação interna, entendendo por diferenciação a capacidade de se relacionar com ambientes diversos e de traduzir a complexidade externa que caracteriza tais ambientes em complexidade interna (em outras palavras, a capacidade de reduzir a multiplicidade e a variabilidade dos ambientes externos dentro de esquemas ou fórmulas de comunicação articuladas e flexíveis de modo a reconduzir dentro dos limites de funcionamento interno do sistema a pluralidade de significados que circulam em um ambiente); portanto é possível distinguir sistemas de alta e baixa diferenciação interna, reconduzindo-os a uma série de fórmulas ou de códigos interpretativos que todo sistema de crença religiosa pretende possuir de forma mais ou menos exclusiva;

3) distinguir, por consequência, dentro dos sistemas de crença religiosa institucionais e não, de alta e baixa diferenciação, aqueles que interagem pouco ou muito com o ambiente eletronicamente aberto e sem limites, utilizando filtros e obstáculos mais ou menos rígidos ou 
então deixando espaço livre ao jogo da comunicação interativa via computador; no primeiro caso lidamos com códigos fechados, no segundo com códigos abertos. Na base desta distinção está, em outras palavras, o modo através do qual um sistema de crença representa a si mesmo via internet: como um vigilante guarda alfandegário que controla seus confins simbólicos, ou então como um generoso atravessador de almas que não tem interesse em defender os próprios confins simbólicos, pois está estruturado conforme o princípio do laissez-faire próprio do mercado da comunicação interativa via computador.

Combinando os três critérios, é possível construir o seguinte quadro, que apresenta algumas das possibilidades de combinação entre esses critérios:

\section{Quadro 1. Ideal-Sitologia}

Hipótese para uma descrição dos ideal-tipos das relnet (religiões em rede) por: Baixa/Alta Diferenciação (BD vs. AD) e por Código Fechado/Aberto de Sentido (CCS vs. CAS).

\begin{tabular}{|c|c|}
\hline $\begin{array}{l}\text { 1T. BD \& CCS (baixa/fechado): } \\
\text { Sistemas de crença institucionais de baixa } \\
\text { diferenciação interna que no sítio (online) } \\
\text { comunicam que sabem controlar os próprios } \\
\text { confins simbólicos, como guardas vigilantes, } \\
\text { em relação a um ambiente externo (offline) } \\
\text { muito mais diferenciado e com uma variedade } \\
\text { de atribuições de sentido a normas, preceitos, } \\
\text { rituais e doutrinas, que podem aparecer } \\
\text { somente pela possibilidade de receber } \\
\text { mensagens, filtrados e colocados em espaços } \\
\text { comunicativos muito limitados em relação ao }\end{array}$ & $\begin{array}{l}\text { 2T. AD \& CAS (alta/aberto): } \\
\text { Sistemas de crenças institucionais de alta } \\
\text { diferenciação interna que no sítio (online) } \\
\text { oferecem uma imagem de si, como se } \\
\text { os confins simbólicos fossem facilmente } \\
\text { superáveis, sem excessivos controles na } \\
\text { alfândega, partindo do pressuposto que a } \\
\text { eventual polissemia e redundância do sentido } \\
\text { presente no ambiente externo (offline) possa } \\
\text { constituir um valor agregado, que aumenta } \\
\text { o desempenho comunicativo de um sistema } \\
\text { aberto e não dogmático. }\end{array}$ \\
\hline $\begin{array}{l}\text { 3T. BD \& CAS (baixa/aberto): } \\
\text { Sistemas de crenças não institucionais de } \\
\text { baixa diferenciação interna que se apresentam } \\
\text { como ambientes com códigos de acesso } \\
\text { abertos ao ambiente externo (offline), } \\
\text { pelos quais o princípio de funcionamento } \\
\text { do sistema depende da quantidade e da } \\
\text { qualidade das intervenções interativas dos } \\
\text { surfers, navegantes em alto mar em botes de } \\
\text { segurança de um navio que já está à deriva, } \\
\text { em busca de uma ilhota onde atracar; o } \\
\text { ambiente online é um lugar onde o sentido } \\
\text { é produzido e um sistema de crença pode } \\
\text { se reproduzir com baixa dispersão de } \\
\text { informação. }\end{array}$ & $\begin{array}{l}\text { 4T. AD \& CCS (alta/fechado): } \\
\text { Sistemas de crença não institucionais de alta } \\
\text { diferenciação interna cujo sítio configura-se } \\
\text { como um espaço bem reconhecível em seus } \\
\text { confins simbólicos, traçados com um design } \\
\text { preciso que transmite a quem está navegando } \\
\text { nele a ideia ou o sentido não de um campo } \\
\text { aberto, mas de um sólido bloco de certezas } \\
\text { doutrinárias e de práticas rituais; por um } \\
\text { lado, existe a imagem de ter de lidar com um } \\
\text { sistema de crença de sólidas tradições, pelo } \\
\text { outro se oferece um ambiente virtual que } \\
\text { aparece bem defendido e delimitado em seus } \\
\text { confins simbólicos: quem entra sente que } \\
\text { pertence a uma comunidade em vez de ser um } \\
\text { isolado free-rider. }\end{array}$ \\
\hline
\end{tabular}


Sítios que desenham eletronicamente um ambiente aberto potencialmente ao ambiente offline podem ser, por exemplo, Sacred Space (http://sacredspace.ie/), gerenciado por um grupo de Jesuítas irlandeses, que oferece, em 23 línguas diversas, conexões para a oração personalizada ou de grupo em rede (terços, novenas, oração para a paz etc.) e um sítio como Dailyzen Meditation (http:// www.dailyzen.com/meditation.asp), que se apresenta como um espaço virtual de meditação zen, onde o usuário pode escolher no lado esquerdo da homepage qual o tipo de meditação prefere fazer via rede ou se pretende adquirir um objeto/amuleto ou então ler as publicações do centro e assim por diante. Nestes casos, em linha de princípio, estamos diante de dois sistemas de crença altamente diferenciados: o catolicismo em uma de suas muitas variantes de modelos de espiritualidade, por um lado, e o budismo em sua variante zen ou chan. Considerações similares podem ser feitas com referência a outro sítio, o Zen Mountain Monastery (http://www.mro.org/zmm), que apresenta em sua homepage as possibilidades oferecidas para meditar em um lugar real de retiro espiritual (e então funciona como uma oferta-venda de serviços) que encaminha, evidentemente, a um complexo sistema de crença, que por definição não coloca filtros ou juramentos de fé preliminar para poder faze parte do mesmo. Já no caso de sistemas de crença não institucionais é muito mais complicado tentar reduzir a vastidão do fenômeno das cyber-religions dentro de tipos ideais, porque podem parecer rígidos demais. Todavia, para retomar as indicações metodológicas que Weber nos indicou quando construiu seus tipos ideais de ação social, um tipo ideal nunca representa, por definição, a realidade: ele é um ponto de observação do pesquisador, observação da observação, modo através do qual o que é real torna-se pensável e tratável cientificamente. Isso significa que não existem tipos puros; na espécie concreta, que pode ser observada no mundo da comunicação mediada pelo computador, é provável encontrar uma série de tipos mistos. À objeção com base na qual alguém poderia afirmar a não utilidade heurística dos tipos ideais responde-se simplesmente que eles servem para começar a compreender um fenômeno que de outra forma seria fugidio, indefinível, considerada sua magnitude (levando em conta que às vezes fala-se, na literatura sociológica, de godcasting ou de godweb...) (Jungblut, 2001). Os tipos ideais servem para começar a se orientar sem cair no descritivismo.

Conscientes, então, dos limites de qualquer tipologia, trata-se de refinar progressivamente um método de análise do fenômeno que apenas há alguns anos está sob o escrutínio dos estudiosos. No caso dos sistemas de crença não institucionais, se por um lado existe algum consenso em identificar o nível de interatividade de sítios que se apresentam como espaços nos quais os 
participantes são protagonistas ativos do doing religion, do fazer uma religião, ou, para ser mais rigorosos com a terminologia da teoria dos sistemas, de produzir sentido (Pace, 2008), por outro lado se discute se efetivamente é possível estabelecer uma diferença nítida entre as religion online em relação às online religion. Tanto Young (2004), mas principalmente Cowan (2004) assinalaram como na prova dos fatos nem sempre seja fácil colocar os vários sítios em uma célula em vez de outra. Cowan, por exemplo, ilustrou o caso dos sítios neo-pagãos ou Wicca (um fenômeno de esoterismo iniciado em 1954 e hoje difundido no mundo inteiro com comunidades, grupos e até igrejas Wicca: para ter uma ideia é possível visitar o portal italiano wicca.it), que muitas vezes funcionam combinando o aspecto informativo "de cima para baixo" (como no caso das religiões em linha) com janelas em que a interação com o exterior é não somente possível, mas também encorajada. Além disso, as observações críticas que Young sugeriu em relação à primeira classificação proposta por Helland, muitas vezes solicitada, são dignas de atenção, pois elas colocam a questão de distinguir a intensidade da comunicação em tempo real que acontece em um sítio em relação a outro. Young sugere, de fato, distinguir entre o modelo one-to-many communication e o many-to-many communication.

Se traduzirmos esta distinção na terminologia da teoria dos sistemas, isto significa começar pela relação sistema-ambiente e estudar o tipo de relação que se estabelece. O que é importante é esta segunda dimensão mais que a primeira que faz referência a uma dupla de conceitos. Então, pode haver sítios em que a comunicação é, por assim dizer, vertical, onde ela se representa (também do ponto de vista da economia do sinal e do design eletrônico) do único ao múltiplo, do alto para um ambiente que por definição presume-se variado, compósito e não facilmente re-con-duzível aos esquemas ou aos princípios autopoiéticos de um determinado sistema de crença; ou então outros em que o procedimento colocado em cena parece, ao contrário, regulado pelo princípio do acréscimo informativo, assegurado por um livre acesso e fluxo de interações com um ambiente que por definição não pode ser contornado. No primeiro caso, para usar a metáfora do compasso, os limites são definidos pelo próprio design do sítio (um caso exemplar é o sítio do Vaticano - vatican.va.it - que anuncia no cabeçalho "portal institucional" ou então o sítio do European Council for the Fatwa: http://www.e-cfr.org), no segundo eles parecem mais paredes móveis (que podem se abrir ou fechar conforme a onda de fluxo que chega do exterior), como no caso de uma página web dedicada à constituição de um sanga (comunidade budista) virtual (Buddhist Portal E-sangha) (Brasher, 2001) ou do sítio que procura interagir com as novas gerações de sikh na 
Europa para tentar transmitir corretamente os símbolos religiosos da tradição com uma linguagem moderna e cativante (Sikh-youth web site). Por fim, um caso interessante é representado pelas igrejas virtuais que regulam a interação por meio de um procedimento que pode parecer coerente com as práticas tradicionais católicas (como a prática da confissão), mas que na realidade funciona como um espaço para publicar as próprias supostas transgressões (os próprios pecados, como continuam a ser denominados nos sítios em questão). De fato, muitas vezes uma pessoa pode enviar por e-mail a sua confissão, da qual permanece um rastro por um determinado período de tempo em uma página do sítio, portanto - mesmo no respeito da privacidade garantida pelo anonimato ou pelas iniciais -, aquela página torna-se uma espécie de espelho da má consciência coletiva, um lixão a céu aberto das deficiências humanas. Se olharmos as páginas web ou da Flamingo Road Church (http://flamingoroad. org/ivescrewed/index.html) ou da Saint Miriam Catholic Apostolic Church of Antioch (http://mysaintmiriam.org), percebe-se como ambas oferecem um espaço para a confissão. A primeira com o slogan "post your confession this is the beginning of a cool journey for you" [envie sua confissão, este é o começo de um bom dia para você]; a segunda com uma frase-chamariz do tipo "there are quite few websites out there that now offer you the ability to confess you sins and wrong doings, but none acutally go - completely confidential (corsivo nel testo) - to an ordained Catholic priest" [há alguns websites por aí que agora the oferecem a capacidade de confessar seus pecados e malfeitos, mas nenhum vai - completamente confidencial (cursivo no texto) até um padre católico ordenado] (na realidade o pastor James St. George, que supervisiona a paróquia com sede em Filadélfia e que gerencia o sítio, não faz parte nem da Igreja católica, romana, nem da Grego-ortodoxa de Antioquia, nem de nenhuma outra Igreja de matriz protestante; de fato, trata-se de uma igreja independente nascida em 1957, na Califórnia, em Santa Barbara, com uma dúzia de dioceses espalhadas no território americano). A diferença entre os dois web, na ótica da ideal-sitologia descrita acima, pode ser percebida melhor se colocarmos a Flamingo Road no Tipo3, enquanto a Saint Miriam (que envia a um sistema mais amplo e complexo, com índices de diferenciação elevada, pois é chamado continuamente a marcar as próprias distâncias e diferenças respectivamente em relação aos três competidores históricos de peso, a Igreja católica, a Ortodoxa e as Protestantes) no tipo 4.

Uma tipologia está em função da metodologia. Se temos um modelo teórico discreto, flexível mas claro, é mais fácil colocar em campo métodos adequados de acordo com a complexidade do fenômeno que pretendemos estudar. 


\section{Da religião à espiritualidade: em busca do cyber-sacred-self}

O complexo mundo da cyber-religion abre, como vimos, cenários em contínua evolução, cujos limites deslocam-se sempre um pouquinho além, e isto apresenta dificuldades objetivas para quem pretende descrever e interpretar este fenômeno. O modelo explicativo recém exposto oferece uma possibilidade que, pelo menos inicialmente, tem condições de ajudar o pesquisador a colocar ordem em um universo constantemente em expansão.

Todavia, há outra questão que merece ser mencionada: o campo da religião na web pode ser interpretado como o efeito não só das inéditas possibilidades oferecidas pelo desenvolvimento tecnológico aplicado à comunicação, também religiosa, mas como uma mudança mais profunda que caracteriza uma nova modalidade de se colocar na posição de indivíduo em relação ao sagrado. A religião em rede, em outros termos, ao mesmo tempo registra e incentiva uma mudança que os sociólogos da religião rotularam como passagem "da religião à espiritualidade". Um deslocamento de atenção que se coloca no sulco ao longo da "revolução silenciosa" descrita por Inglehart (1983) como passagem dos valores materialistas aos valores pós-materialistas: da segurança física e econômica, à ênfase sobre a autorrealização pessoal e sobre necessidades intelectuais e estéticas. Uma passagem que evidencia tanto o crescente papel do indivíduo dentro das diversas dinâmicas sociais, como também o declínio da legitimidade reconhecida à autoridade hierárquica e às instituições em geral, inclusive as religiosas.

As reflexões de Inglehart são retomadas por Bellah (1996) quando, ilustrando os elementos expressivos de nossa cultura, afirma que eles levam a interpretar o sentido da existência na perspectiva do bem estar individual mais que como resposta a compromissos e obrigações de tipo moral. Embora o fundar por si mesmo o significado da própria existência seja um apoio frágil para efetuar escolhas importantes, isto torna possível a construção de um sistema de significados que tem condições de adaptar-se rapidamente às situações sempre novas da vida quotidiana. Além disso, estes fundamentos, apesar de frágeis, têm todavia a vantagem de fazer com que se perceba o curso da vida como um "tornar-se cada vez mais si mesmos", sem fixar-se rigidamente em um ou outro ponto do percurso: um caminho em descoberta de si mesmo, sem se deter demais sobre aquilo que poderia tornar-se um peso ou um obstáculo.

Durante os anos noventa do século passado e no início do novo século vários autores refletiram sobre esta nova percepção que o indivíduo tem de si mesmo, e sobre as consequências que este posicionamento tem sobre o 
lado individual e também sobre o coletivo. Taylor (1989, 1991, 2002), por exemplo, aprofunda a "cultura de si", e mais precisamente a "virada subjetivística" da cultura contemporânea. Ela consiste na recusa por parte do homem contemporâneo a viver a própria existência em exclusivo obséquio a papéis objetivos que lhe são impostos de fora, e isto para poder estar em sintonia com o "si profundo" que, de dentro de cada um, sugere quais são as tarefas a serem assumidas, as maneiras de executá-las, os juízos a serem dados. Isto é ao mesmo tempo causa e efeito de um modo reflexivo de enfrentar a vida e os acontecimentos, não mais em obediência acrítica a hábitos e regras externas, mas em sintonia com as exigências do "si profundo", o qual mais que à verdade objetiva está atento à autenticidade subjetiva (Vannini; Williams, 2009). Esta virada da exterioridade à interioridade leva consigo uma atenção específica para as emoções, os sentimentos, os sonhos, as lembranças, o corpo, a compaixão, as experiências individuais da vida.

Não cabe aqui ressaltar como o deslocamento de atenção entre a ordem preestabelecida por um sistema qualquer de significado objetivo, como, por exemplo, se cristaliza nas instituições religiosas, para as exigências do indivíduo assim como ele mesmo as percebe, traz como consequência a nova compreensão da relação entre o indivíduo e o contexto social e cultural no qual está inserido; e, especificamente isto, traz consequências sobre a relação entre o indivíduo crente e as instituições que desde sempre regulam a relação com o sagrado. Em extrema síntese, podemos afirmar que na época contemporânea o "sagrado si" torna-se a fonte de significado e a única autoridade a ser obedecida. A espiritualidade, entendida nesta perspectiva, consiste exatamente no deslocamento do eixo de legitimação do sagrado da autoridade externa da instituição religiosa à liberdade de escolha do indivíduo, o qual se relaciona ao transcendente, de qualquer maneira seja representado, não em obediência a comandos externos, mas seguindo criativamente um itinerário de busca que responda às exigências do "sagrado si" (Giordan 2006, 2007).

O deslocamento do eixo de legitimação do sagrado da instituição ao indivíduo coloca imediatamente a questão da autoridade, questão que como vimos anteriormente é central na análise da religião como comunicação mediada pelo computador. Analisando o ator social que se põe a digitar no teclado do computador em busca na web de material religioso, podemos dizer que ele efetua uma pesquisa propriamente "religiosa", ou então responde àquela dinâmica de pesquisa livre e criativa que rotulamos como "espiritualidade"? Obviamente não é questão de palavras, mas de entender qual é o valor em jogo quando o sagrado torna-se disponível à pesquisa na web. O ponto de 
partida é exatamente a pesquisa, ou melhor, o impulso que leva o indivíduo a não se satisfazer com as ofertas de sentido que encontra no comércio na realidade, e a atender a curiosidade de navegar no virtual. Uma pesquisa que evidencia um dos traços mais característicos da cultura contemporânea, aquele da reflexividade, que consiste em não dar nada como certo, nem mesmo aquelas verdades que até pouco tempo atrás eram consideradas indiscutíveis e por isso não eram discutidas. Uma pesquisa que, como sublinhou Roof (1993), se caracteriza pela viagem, a descoberta, às vezes até o vagar sem uma meta precisa, sonhando um próprio sistema de significado "cortado sob medida" (tailor-made meaning system). Exatamente como quando na internet navega-se passando de um sítio a outro, por meio de link, associações de ideias, casualidade.

Ligada à questão da autoridade existe a outra que toca as crenças: se os confins tornam-se permeáveis, facilmente superáveis, porosos, se o internauta pode com extrema facilidade transgredir os limiares da verdade definida dogmaticamente, abre-se o espaço para uma religious imagination virtualmente sem confins; não somente se fundem e con-fundem imagens diferentes de Deus, mas nos abrimos para a descoberta de energias cósmicas e de potências criativas que a força da web substancia e amplifica. A verdade, neste contexto, cede o passo à autenticidade, a qual responde à necessidade de estar em sintonia consigo mesmo, de bem estar pessoal, de descoberta do "verdadeiro si". O cyber espaço não faz outra coisa a não ser responder a esta busca do si autêntico, multiplicando praticamente ao infinito as possibilidades de encontrar resposta à necessidade de sentido. E isto, como vimos, a expensas das instituições que à necessidade de sentido respondem com a norma definida, com crenças exclusivas, com práticas precisas que marcam o limite de maneira a tornar imediatamente identificável quem é in e quem é out (Hoover e Clark 2002; Dawson e Cowan 2004).

Contrariamente ao pensamento de Heelas e Woodhead (2005), a referência "objetiva" à instituição do crer, é bom que fique claro, não se torna um fenômeno residual; é somente destinado a perder o seu caráter absoluto. Também as instituições religiosas tradicionais, não querendo ou não podendo se subtrair ao palco do cyberspace, entram realmente na lógica da competição democrática com as outras instituições ou com os outros grupos que oferecem bens e serviços religiosos/espirituais: é a lógica que responde à demanda destes bens e serviços, feita por indivíduos que estão à procura do “cyber-sacred-self”. A web, em definitiva, não muda somente o modo de crer, mas muda também o modo de "fazer crer" por parte das religiões históricas (Babin e Zukowski 2002; Brascher 2004; Bailey 2007). 
Ainda são muitas as questões que permanecem abertas e que deverão ser estudadas de maneira específica: como muda o conceito de "experiência" quando entra no "virtual" da rede? Que tipo de identidade pode ser construído nos contínuos envios a outros links típicos das páginas web? O além da rede como por-forma, trans-forma, e de-forma o além do mistério? O estar conectados à web amplifica a necessidade de connection com os outros, ou simplesmente a diminui e esteriliza os possíveis aspectos conflituosos? São perguntas que de alguma forma já foram enfrentadas, mas que assim mesmo devem ser mantidas constantemente sob controle: a religião na web é um fenômeno novo que não se presta a conclusões apressadas e definidas. Não há dúvidas que estamos somente no começo de um fenômeno que está destinado a mudar a forma com que o indivíduo coloca-se em relação ao sagrado: uma modalidade mais espiritual que religiosa, que as inovações tecnológicas por um lado apenas percebem e amplificam, e pelo outro lado criam ex novo em uma experimentação contínua e aparentemente infinita.

\section{Referências}

ASAMOAH-GYADU, Kwabena. Anoiting to the sacred. Neo-pentecostal and televised christianity in Ghana. Studies in World Christianity, v. 1, p. 9-28, 2005.

BABIN, Pierre; ZUKOWSKI, A. Ann. The gospel in cyberspace. Nurturinging faith in the internet age. Chicago: Loyola Press, 2002.

BARNA RESEARCH GROUP More Americans are seeking Net-based faith experiences, 2001. <http://www.barna.org/cgibin>.

BAILEY, Brian. The blogging Church. Sharing the story of your church through blogs. San Francisco: Jossey-Bass, 2007.

BELLAH, Robert. Le abitudini del cuore. Individualismo e impegno nella società complessa. Roma: Armando, 1996.

BERZANO, L.; GENOVA, C. I lifestyles nella partecipazione religiosa. Torino: Il Segnalibro, 2008.

BRASHER, E. Brenda. Give me that online religion. San Francisco: Jossey-Bass, 2001.

BRASHER, E. Brenda. Give me that online religion, New Brunswick: Rutgers University Press, 2004.

CAMPBELL, Heidi. Making space for religion in internet studies. The Information Society, Cedar Rapids, Indiana, v. 4, p. 309-315, 2005.

COWAN, E. Douglas. Cyberhenge: modern pagans on the internet. New York: Routledge, 2004.

DAWSON, Lorne L.; COWAN, E. Douglas (eds.). Religion online. Finding faith on the internet. New York: Routledge, 2004. 
DAYAN, Daniel; KATZ, Elihu. Armachair Pilgrimage. On Film, v. 13, p. 25-34, 1984.

DAYAN, Daniel; KATZ, Elihu. Media events, Cambridge: Harvard University Press, 1992. (Trad. it: Le grandi cerimonie dei media. Bologna: Baskerville, 1995).

FATH, Sébastien. Dieu XXL. La révolution des megachurches. Paris: Autrement, 2008.

GIORDAN, Giuseppe (a cura di). Tra religione e spiritualità. Il rapporto con il sacro nell'epoca del pluralismo. Milano: Franco Angeli, 2006.

GIORDAN, Giuseppe. Spirituality: from a religious concept to a sociological theory. In: FLANAGN, Kieran; JUPP, Peter J. (eds.). A Sociology of spirituality. Aldershot: Ashgate, 2007.

GUIZZARDI, Gustavo (a cura di). La narrazione del carisma. Torino: RAI-ERI, 1986.

GUIZZARDI, Gustavo. Esserci anche dopo, l'agonia mediatica del carisma. Religioni e Società, Pisa, Itália, v. 53, 2005. p. 10-19.

HADDEN, Jeffery; COWAN, Douglas. Religion on the internet. Research prospects and promises. New York: Jai Press, 2000.

HEELAS, Paul; WOODHEAD, Linda. The spiritual revolution. Why religion is giving way to spirituality. Oxford: Blackwell, 2005.

HELLAND, Christopher. Online-religion/religion online and virtual communitas. In: HADDEN, Jeffery; COWAN, Douglas. Religion on the internet. Research prospects and promises. New York: Jai Press, 2000. p. 205-224.

HELLAND, Christopher. Online religion as lived religion: methodological issues in the study of religious participation on the internet. In: Online Heidelberg Journal of Religions on the Internet, 17, 2005. < http://www.ub.uni-heidelberg.de/archiv/>.

HELLAND, Christopher. Diaspora on the electronic frontier: developing virtual connections with Sacred Homelands. Journal Computer-Mediated Communication, Heidelberg, Alemanha, v. 3, p. 956-976, 2007.

HERVIEU-LÈGER, Danièle. La religion pour mémoire. Paris: Cerf, 1993. (Trad. it: Religione e memoria. Bologna: Il Mulino, 1996).

HOJSGAARD, Martin; WARBURG, Margit (eds.). Religion and cyberspace. New York: Routledge, 2005.

HOOVER, Stewart; SCHOFIELD, Clark Lynn (eds.). Practicing religion in the Age of the Media. New York: Columbia University Press, 2002.

INGLEHART, Ronald. La rivoluzione silenziosa. Milano: Rizzoli, 1983.

JUNGBLUT, Airton. Os recantos de sagrado no ciberespaco, paper presentato alla XI Jornadas sobre Alternativas Religiosas en America Latina. Santiago de Chile, 3-5 ottobre 2001.

LOACHHEAD, David. Shifting realities: information technology and the church. Genève: WCC, 1997.

O'LEARY, Stephen; BRASHER, Brenda (eds.). The unknown god of the internet. Albany, State University of New York, 1996. 
MIT COMMUNICATIONS FORUM. Religion and Internet, April 18, 2002. $<$ http.// web.mit.edu/comm.-forum/forums/religion.html $>$.

PACE, Enzo. Raccontare Dio. La religione come comunicazione. Bologna: Il Mulino, 2008.

PEW FORUM. Internet for Religion, 2002. < Pew Internet.org/report>.

ROOF, W. Clark. A generation of seekers. The spiritual journeys of the Baby Boom Generation. San Francisco: Harper Collins, 1993.

STOLZ, Jorge (ed.). Salvation goods and religious markets. New York: Peter Lang, 2008.

TAYLOR, Charles. Sources of the self: the making of the modern identity. Cambridge: Cambridge University Press, 1989.

TAYLOR, Charles. The ethics of authenticity. Cambridge: Harvard University Press, 1991.

TAYLOR, Charles. Varieties of religion today. Cambridge: Harvard University Press, 2002.

THUMMA, S. Religion and the internet. Cambridge: Mit Communications Forum, 2002. <http://web.mit.edu/>.

VANNINI, Phillip; WILLIAMS, J. Patrick (eds.). Authenticity in culture, self, and society. Aldershot: Ashgate, 2009.

YOUNG, Glenn. Reading and praying on line. In: DOWSON, Lorne; COWAN, Douglas (eds.). Religion online. New York: Routledge, 2004. p. 93-106.

Data de recebimento: 18.04 .2012

Data de aprovação: 28.09.2012 